\title{
Long-term outcomes of intravitreal injection of bevacizumab for choroidal neovascularization associated with choroidal osteoma
}

This article was published in the following Dove Press journal:

Clinical Ophthalmology

3 March 2015

Number of times this article has been viewed

\section{Tadanobu Yoshikawa \\ Kanji Takahashi}

Department of Ophthalmology, Kansai Medical University, Osaka, Japan
Correspondence: Tadanobu Yoshikawa Department of Ophthalmology, Kansai Medical University, 5-I Shinmachi, 2-Chome, Hirakata, Osaka 573-10I0, Japan

Tel +8I 72804 0l0। (ext. 56266)

Fax +8I 728042039

Email yoshikat@takii.kmu.ac.jp
Purpose: To describe the outcomes of intravitreal injections of bevacizumab for choroidal neovascularization (CNV) associated with choroidal osteoma.

Methods: Retrospective consecutive case series. Three eyes of three patients were studied. All patients were treated with intravitreal injections of bevacizumab for CNV associated with choroidal osteoma. Best-corrected visual acuity, central foveal thickness, tumor thickness on spectral domain optical coherence tomography, and subretinal pigmentation around the CNV were evaluated.

Results: The mean number of intravitreal injections of bevacizumab was 2.0 (range 1-3). The mean follow-up time was 56.0 months (range 25-99 months). The mean LogMAR visual acuity worsened from 0.1 to 0.6 . LogMAR visual acuity loss of 0.7 or worse occurred in two of three eyes. CNV was located in the subfoveal area in two eyes, and CNV was located in the juxtafoveal area in one eye. The mean central foveal thickness decreased from $407 \mu \mathrm{m}$ to $251 \mu \mathrm{m}$. The mean tumor thickness decreased from $709 \mu \mathrm{m}$ to $608 \mu \mathrm{m}$. All eyes had subretinal pigmentation around the $\mathrm{CNV}$.

Conclusion: Intravitreal injections of bevacizumab for subfoveal CNV associated with decalcified choroidal osteoma resulted in poor visual acuity.

Keywords: choroidal osteoma, choroidal neovascularization, bevacizumab, Avastin, vascular endothelial growth factor

\section{Introduction}

Choroidal osteoma is a rare benign intraocular tumor of the choroid that was first reported by Gass et $\mathrm{al}^{1}$ in 1978 . Tumors comprising mature bone are often found in healthy young women. ${ }^{2}$ Despite the tumors being benign, choroidal osteomas showed evidence of growth in $51 \%$ of eyes after 10 years. ${ }^{3}$ Visual acuity loss of three lines or more and $20 / 200$ or worse occurred in $45 \%$ and $56 \%$ of patients after 10 years, respectively. ${ }^{3}$ Some factors resulted in poor visual acuity, such as choroidal neovascularization (CNV) and subretinal fluid attributed to retinal pigment epithelium (RPE) atrophy with choroidal osteoma. ${ }^{3} \mathrm{CNV}$ was related to choroidal osteoma at the 10-year follow-up in $31 \%$ of patients, ${ }^{3}$ but the definitive management of CNV associated with choroidal osteoma has not been established. Laser photocoagulation, surgical removal of CNV, transpupillary thermotherapy, and photodynamic therapy (PDT) have been used as treatments for CNV with choroidal osteoma. ${ }^{4-7}$ However, these therapies have had limited success. Some case reports showed that intravitreal injection of antivascular endothelial growth factor (anti-VEGF) antibodies such as bevacizumab and ranibizumab was moderately effective for CNV secondary to choroidal osteoma in the short term from 4 months to 10 months..$^{8-12}$ However, there is little information related to 
long-term outcomes for intravitreal injection of anti-VEGF drugs for CNV. Recently, Khan et $\mathrm{al}^{13}$ showed that serial anti-VEGF injections with or without PDT for CNV with choroidal osteoma resulted in anatomical improvement and modest long-term visual gains, but the study included only eight eyes. Thus, the aim of the present study was to assess the efficacy of anti-VEGF injection for CNV associated with choroidal osteoma.

\section{Methods}

\section{Subjects}

The medical charts of three eyes of three consecutive Japanese patients with choroidal osteoma were reviewed. The patients were diagnosed as having choroidal osteoma and CNV at Kansai Medical University, Osaka, Japan, from 2006 to 2014.

\section{Examination and diagnosis of CNV related to choroidal osteoma}

All patients underwent a complete ophthalmologic examination including indirect ophthalmoscopy, slit-lamp biomicroscopy, ultrasonography, spectral domain optical coherence tomography (SD-OCT; Spectralis, Heidelberg Engineering, Heidelberg, Germany) and/or RTVue-100 (Optovue, Fremont, CA, USA), color fundus photography, and fluorescein angiography. Two retinal specialists (KT and TY) evaluated the patient data. Activity of CNV was evaluated by fluorescein angiography and SD-OCT. Central foveal thickness was measured with SD-OCT. Central foveal thickness was defined as the distance between the vitreoretinal surface and the anterior surface of the RPE at the foveal area.

\section{Measurement of choroidal osteomas}

The thicknesses of the choroidal osteomas were measured over time using enhanced depth imaging (EDI) of SD-OCT (Spectralis) of the greatest lesion thickness. The greatest lesion thickness was defined as the maximum discernible distance between the innermost and outermost reflex of the choroidal osteoma. To improve the accuracy, measurements of the greatest lesion thickness with EDI-OCT for each eye were registered along the same axis. Because Spectralis was introduced in our hospital in 2011, we did not have records of EDI-OCT results before 2011.

The stage of the choroidal osteoma was defined by tumor color and SD-OCT findings. The calcified region was clinically recognized as yellow-orange as a consequence of an intact RPE overlying the tumor. The decalcified region was recognized as a yellow-gray area and occurred as a result of thinning and depigmentation of the overlying RPE.

\section{Intravitreal injections of bevacizumab}

Patients were treated with $1.25 \mathrm{mg} / 0.05 \mathrm{~mL}$ intravitreal injections of bevacizumab (IVB) (Avastin; Genentech, South San Francisco, CA, USA). Briefly, patient eyes were sterilized with povidone-iodine and injected with $0.05 \mathrm{~mL}$ bevacizumab into the vitreous cavity through the pars plana, $4.0 \mathrm{~mm}$ posterior to the limbus. Retreatment was performed at the discretion of the physician, based mainly on the amount of subretinal fluid determined by SD-OCT. The risks and benefits of IVB were explained to all patients. Approval was obtained from the Institutional Review Board of Kansai Medical University and from all patients. None of the eyes had previously received intravitreal injection of ranibizumab, pegaptanib, or aflibercept.

\section{Main outcome measures}

Best-corrected visual acuity, central foveal thickness, thickness of the choroidal osteoma, subretinal pigmentation, and clinical characteristics (eg, sex distribution and age) were evaluated.

\section{Results}

Of the three choroidal osteoma patients with CNV, two patients were male and one patient was female. The age of the patients was $33.6 \pm 19.5$ years (mean \pm standard deviation [SD]) with a range of $14-53$ years. All patients had a choroidal osteoma in the left eye. The follow-up time from the initial to the final visit was $56.0 \pm 38.4$ months (mean \pm SD) with a range of 25-99 months. The follow-up time from initial therapy with IVB to the final visit was $41.0 \pm 16.7$ months (mean $\pm \mathrm{SD}$ ) with a range of 23-56 months (Table 1).

Two eyes with choroidal osteoma had a decalcified lesion in the fovea, and the other eye with a choroidal osteoma had a calcified lesion in the fovea. Two eyes had CNV located in the subfoveal area, and the other eye had CNV located in the juxtafoveal area. The mean number of IVB injections was 2.0 (range 1-3). None of the eyes had received either PDT or photocoagulation for $\mathrm{CNV}$. Their decimal visual acuity had a range of $0.7-0.9$ at the initial visit and a range of $0.1-0.7$ at the final visit (Table 1).

IVB reduced the central foveal thickness in all eyes, although exudation from CNV in case 3 relapsed after treatment. The mean central foveal thickness decreased from $407 \mu \mathrm{m}$ to $251 \mu \mathrm{m}$. Maintenance of visual acuity in case 1 was associated with a reduction in central foveal thickness. 
Table I Clinical characteristics of choroidal osteoma patients

\begin{tabular}{|c|c|c|c|c|c|c|c|c|c|c|}
\hline \multirow{2}{*}{$\begin{array}{l}\text { Case } \\
\text { number }\end{array}$} & \multirow{2}{*}{$\begin{array}{l}\text { Age } \\
\text { (years) }\end{array}$} & \multirow[t]{2}{*}{ Sex } & \multirow{2}{*}{$\begin{array}{l}\text { Affected } \\
\text { eye }\end{array}$} & \multirow{2}{*}{$\begin{array}{l}\text { Stage of } \mathrm{CO} \\
\text { at fovea }\end{array}$} & \multirow{2}{*}{$\begin{array}{l}\text { Location } \\
\text { of CNV }\end{array}$} & \multirow{2}{*}{$\begin{array}{l}\text { Number } \\
\text { of IVB }\end{array}$} & \multicolumn{2}{|c|}{ Follow-up (months) } & \multicolumn{2}{|l|}{ BCVA } \\
\hline & & & & & & & All periods & $\begin{array}{l}\text { Initial IVB } \\
\text { to final visit }\end{array}$ & Initial visit & Final visit \\
\hline I & 34 & Male & Left & Calcified & Juxtafoveal & 2 & 44 & 44 & 0.7 & 0.7 \\
\hline 2 & 53 & Male & Left & Decalcified & Subfoveal & I & 99 & 56 & 0.9 & 0.2 \\
\hline 3 & 14 & Female & Left & Decalcified & Subfoveal & 3 & 25 & 23 & 0.8 & 0.1 \\
\hline
\end{tabular}

Abbreviations: CO, choroidal osteoma; CNV, choroidal neovascularization; IVB, intravitreal injections of bevacizumab; BCVA, best-corrected visual acuity.

The central foveal thickness of case 2 became thinner after IVB. However, visual acuity worsened as a consequence of thinning of the central foveal thickness. In case 3 , IVB showed a partial effect for CNV, and the central foveal thickness was transiently decreased after IVB. Finally, LogMAR visual acuity worsened and the central foveal thickness did not improve (Figure 1). Mean LogMAR visual acuity of all patients worsened from 0.099 to 0.618 .

The tumor thickness of the choroidal osteoma using SD-OCT was $709 \pm 299 \mu \mathrm{m}$ (mean \pm SD) with a range of 408-1,007 $\mu \mathrm{m}$ from the initial SD-OCT findings and $608 \pm 309 \mu \mathrm{m}$ (mean $\pm \mathrm{SD}$ ) with a range of 305-924 $\mu \mathrm{m}$ from the final SD-OCT findings. In case 3 , the choroidal osteoma was temporarily thickened after IVB. The tumor thickness in all three choroidal osteoma patients tended to decrease over time (Figure 2).

In case 1 , subretinal pigmentation dramatically appeared around the CNV. The appearance of the subretinal pigmentation was accompanied by development of CNV, and subretinal pigmentation and subretinal fluid disappeared after IVB treatment. In addition, SD-OCT showed that the retinal structure in the foveal area was not destroyed (Figure 3).

In case 2, fundus examination revealed yellow-white lesions of approximately five disk diameters in size with a strong deposition of subretinal pigmentation below the fovea. CNV was located in the subfoveal area. Although IVB decreased the exudation of CNV and retinal edema, the retinal layer was disrupted by the RPE atrophy (Figure 4).
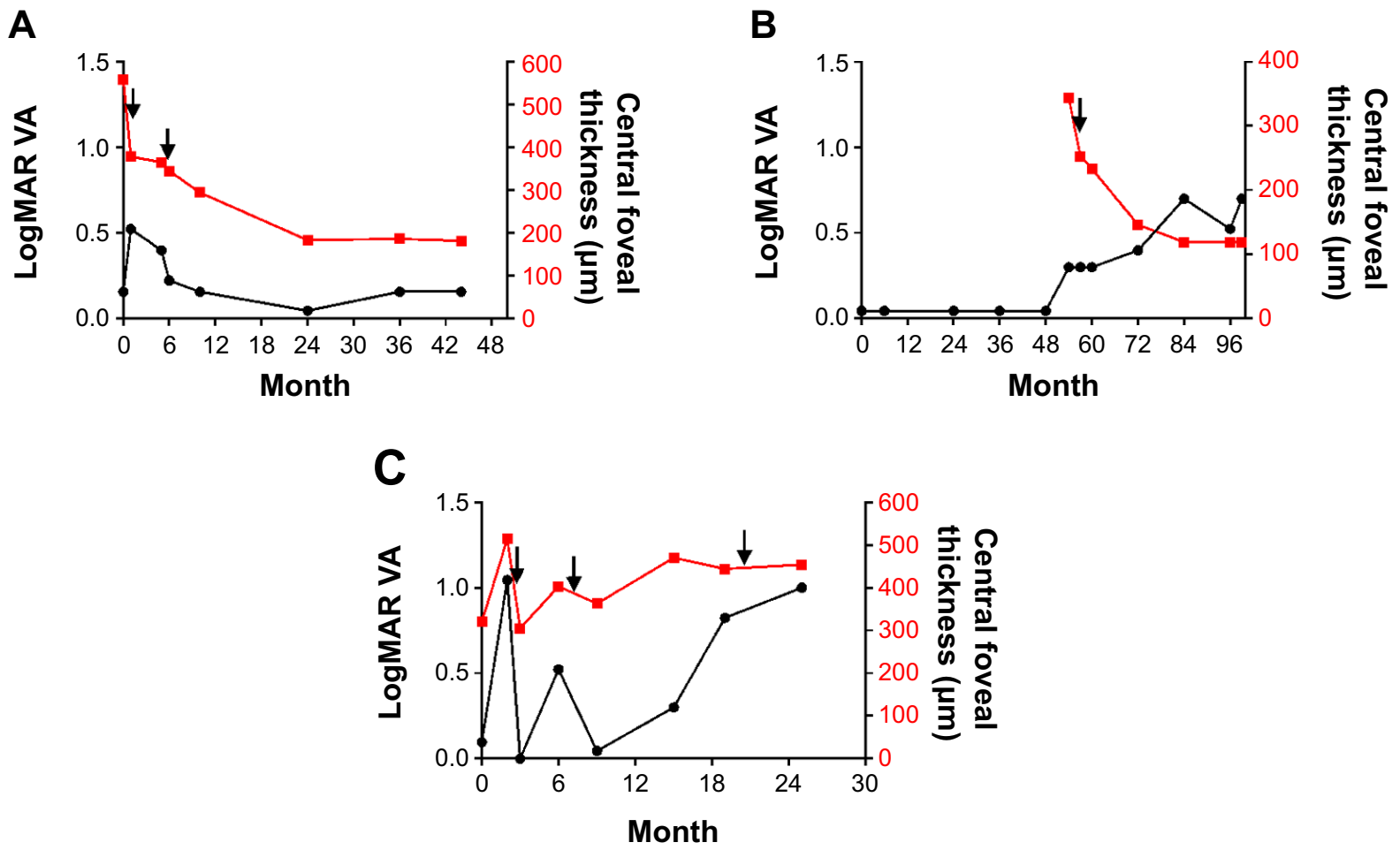

Figure I Response of choroidal osteoma to intravitreal injections of bevacizumab.

Notes: The left and right vertical axes in the graph represent LogMARvisual acuity (VA) and central foveal thickness, respectively. The horizontal axis is the time course from the initial visit. (A) In case I, VA was temporarily decreased. However, at the final follow-up, the central foveal thickness was I8I $\mu$ m and LogMAR VA was 0.15 . VA remained unchanged at the final visit compared with the initial visit. (B) In case 2, central foveal thickness was decreased from $343 \mu \mathrm{m}$ to II $9 \mu \mathrm{m}$. LogMAR VA changed from 0.04 to 0.69 . There were no data on the central foveal thickness before 54 months because we introduced spectral domain optical coherence tomography in our hospital in 2009. (C) In case 3, the central foveal thickness was $454 \mu \mathrm{m}$ at the final visit. VA temporarily improved, but LogMAR VA changed from 0.09 to I.00. Arrows denote intravitreal injections of bevacizumab. 
A

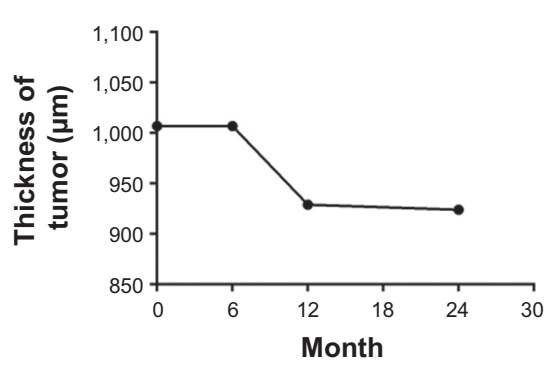

B

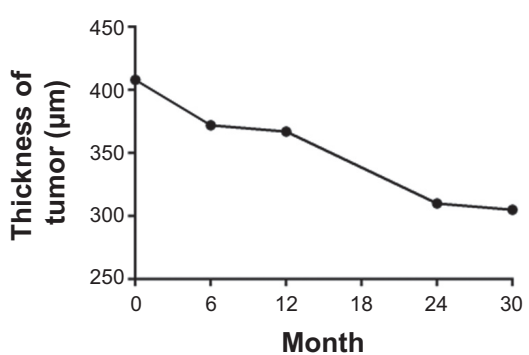

C

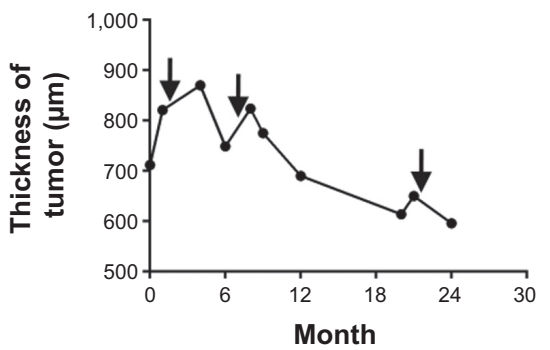

Figure 2 Thickness of the choroidal osteoma using enhanced depth imaging optical coherence tomography.

Notes: The vertical axis is the thickness of the tumor. The horizontal axis is the time course from the first enhanced depth imaging optical coherence tomography measurement. (A) Case I, (B) case 2, and (C) case 3. The thickness of the choroidal osteoma was decreased in all cases at the final follow-up. (C) Intravitreal injections of bevacizumab (arrow) temporarily increased the tumor thickness.

In case 3 , fundus photography and SD-OCT showed that subretinal pigmentation occurred near the CNV. The color of the subretinal pigmentation was pale after treatment with three IVBs. Similar to case 2, SD-OCT revealed residual cystoid macular edema and a disrupted retinal layer in the foveal area (Figure 5).

\section{Discussion}

The main reason for visual loss with choroidal osteoma is decalcification of the tumor, because a decalcified lesion leads to $\mathrm{CNV}$, disruption of the RPE, and appearance of subretinal fluid. ${ }^{3}$ Shields et al $^{3}$ reported that CNV occurred in the bed of decalcification in four $(67 \%)$ of six eyes. In our study, CNV arose from decalcified lesions in two (66\%) of three eyes. We suggest that there are two possibilities for the development of CNV related to a decalcified lesion. First, decalcification of a tumor might induce disruption or thinning of the RPE, Bruch's membrane, and choriocapillaris. Indeed, we showed a decalcified lesion-induced atrophy of the RPE and choriocapillaris. Second, the retina overlying the tumor may be chronically stimulated by the decalcified lesion, and the decalcified tumor may elevate the expression of vascular endothelial growth factor (VEGF) in the retina.

It is known that IVB improves visual acuity in secondary $\mathrm{CNV}$ (eg, myopic $\mathrm{CNV}^{14}$ and pseudoxanthoma elasticum $\mathrm{CNV}$ ) ${ }^{15}$ and idiopathic $\mathrm{CNV}$ patients. ${ }^{16}$ Moreover, in earlier studies, intravitreal injections of anti-VEGF antibodies for CNV secondary to choroidal osteoma also improved visual acuity in the short term. ${ }^{8-12}$ However, posttreatment visual acuity of 20/100 or worse was found in three of five reports. $^{8-12}$ A long-term follow-up study, which included intravitreal injection of anti-VEGF antibodies with or without PDT consolidation for CNV with choroidal osteoma, showed that the mean Snellen visual acuity improvement was one \pm four lines at a mean of 32 months of follow-up..$^{13}$ Additionally, Khan et a ${ }^{13}$ showed that resolution of subretinal fluid on OCT was achieved in seven of eight eyes. The present study showed that the disappearance of subretinal fluid was found in two of three eyes, but IVB resulted in visual acuity of $20 / 100$ or worse in two of three eyes at a mean of 56.0 months of follow-up. Because PDT may be associated with decalcification of tumors, we did not treat with PDT for CNV associated with choroidal osteoma.

We speculate that there are three possibilities for poor visual acuity in our patients. First, visual acuity may be determined by the number of injections of anti-VEGF drugs. Khan et al ${ }^{13}$ treated patients with serial intravitreal injection of ranibizumab or IVB with a mean of 12.3 injections. However, our patients received IVB with a mean of 2.0 injections at the discretion of the physician. Moisseiev et al ${ }^{17}$ reported that the mean vitreal half-life for IVB was 4.9 days. Thus, serial and multiple injections for $\mathrm{CNV}$ associated with choroidal osteoma may help to maintain good visual acuity. However, it is possible that intravitreal injections of anti-VEGF drugs infrequently caused menstrual irregularities. ${ }^{18}$ Because choroidal osteoma is usually found in young women, it may be difficult to use serial and multiple injections of anti-VEGF drugs. Second, it can be assumed that the stage of a tumor is also associated with the outcome of visual acuity. Shields et al ${ }^{19}$ examined 22 cases of choroidal osteoma and reported that decalcified subfoveal choroidal osteoma was associated with poor visual acuity. Although IVB decreased exudation of CNV, decalcified choroidal osteoma damaged the RPE and choriocapillaris. Thus, IVB for CNV with decalcified choroidal osteoma may have limited efficacy. Third, the location of the CNV may be associated with poor visual acuity. The present study showed that two eyes with CNV were located in the subfoveal area. Subfoveal CNV is likely to disrupt the retina at the foveal area more than juxtafoveal CNV. Consequently, our patients were likely to have poor visual acuity.

The predictive factors for $\mathrm{CNV}$ in patients with choroidal osteoma include an irregular surface on the tumor and 

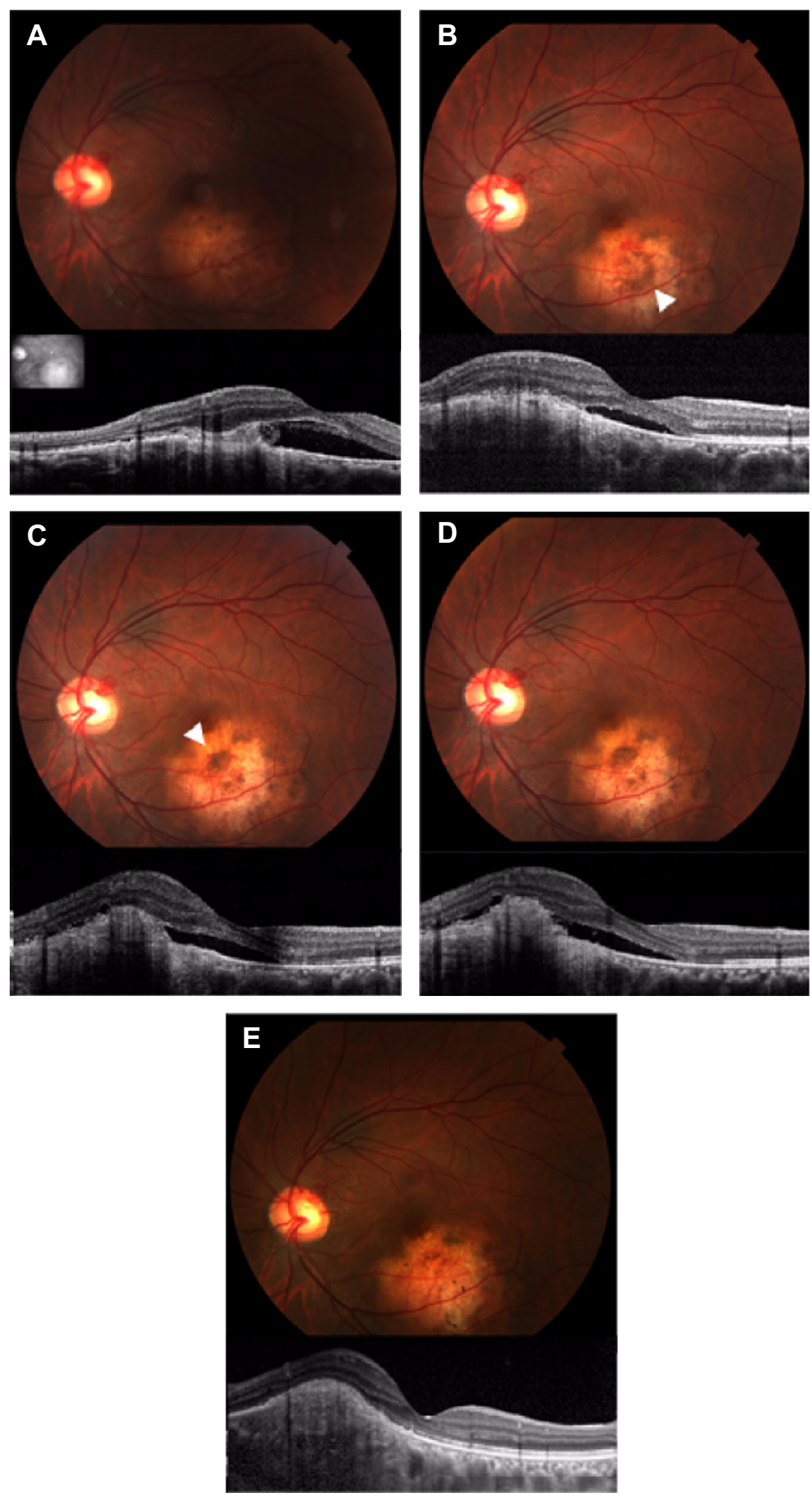

Figure 3 Photograph and spectral domain optical coherence tomography findings for case $\mathrm{I}$.

Notes: (A) First visit. Spectral domain optical coherence tomography shows choroidal neovascularization (CNV) with subretinal fluid located in the juxtafoveal area. Insert shows fundus image for scan marking. (B) One month after the first visit. Photograph showing subretinal pigmentation (arrowhead) around the CNV with subretinal hemorrhage. (C) Five months after the first visit. The patient had a recurrence of CNV and new subretinal pigmentation (arrowhead) around the CNV. (D) Six months after the first visit. Subretinal fluid and CNV remained unchanged approximately I month after intravitreal injections of bevacizumab. (E) Eighteen months after the first visit. Subretinal pigmentation and subretinal fluid disappeared. Spectral domain optical coherence tomography showed that the retinal structure in the subfoveal area did not disappear. 

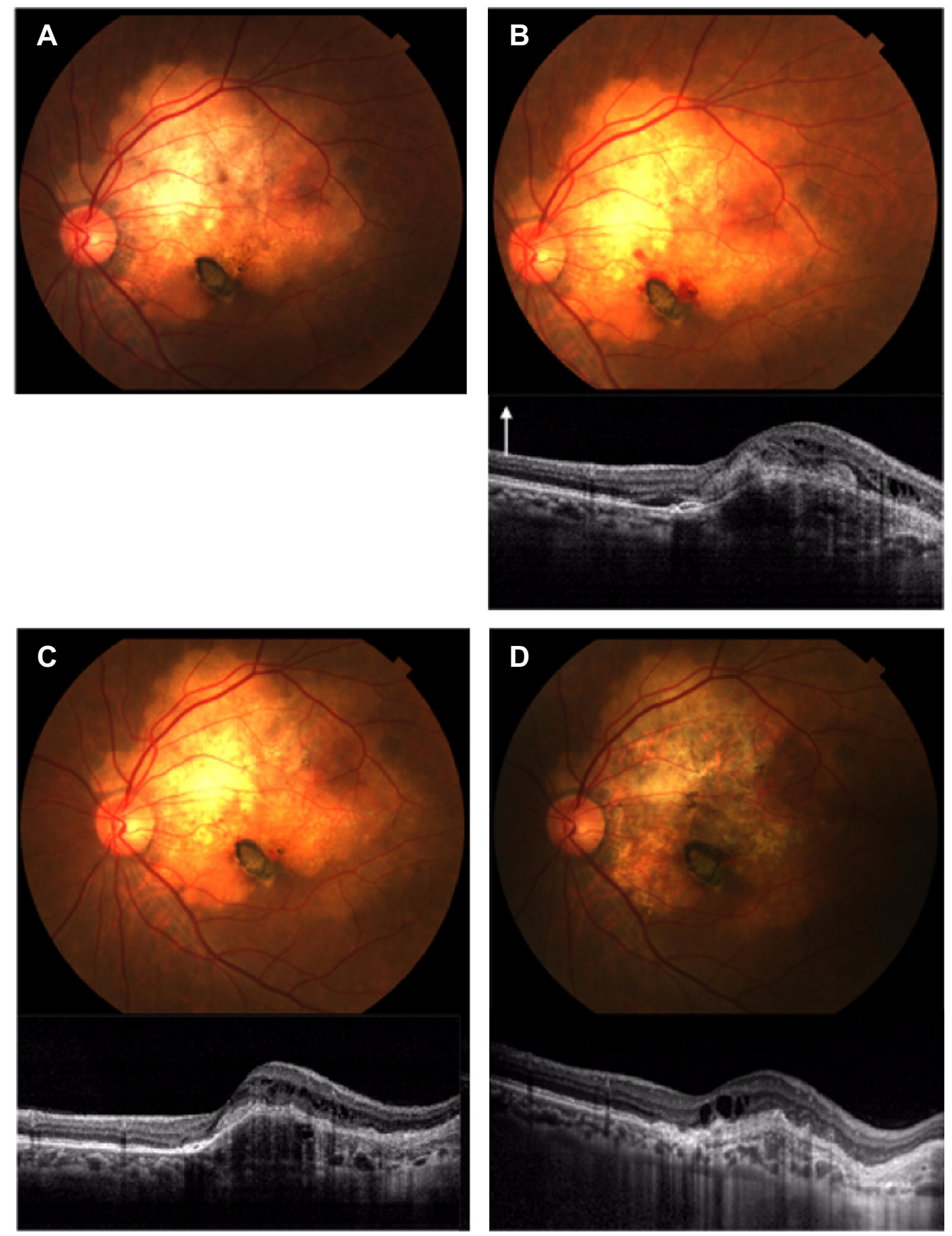

Figure 4 Photograph and spectral domain optical coherence tomography (SD-OCT) findings for case 2.

Notes: (A) Thirty-one months after the first visit. A fundus photograph shows yellow-white lesions of approximately five disk diameters in size. There is no SD-OCT findings in the first visit of case 2. (B) Forty-three months after the first visit. SD-OCT shows subfoveal choroidal neovascularization with retinal edema and subretinal fluid. White arrow denotes longitudinal scans of the SD-OCT. (C) Forty-seven months after the first visit. Intravitreal injections of bevacizumab decreased the choroidal neovascularization and subretinal fluid. (D) Ninety-nine months after the first visit. Fundus photograph and SD-OCT show retinal pigment epithelium atrophy.

subretinal hemorrhage on the tumor; the relative risks of these factors were 10.6 and 15.1 in multivariate analysis, respectively. ${ }^{3}$ In our series of three eyes with choroidal osteoma, all eyes had these factors. Furthermore, our study presented new information on subretinal pigmentation around the $\mathrm{CNV}$ in choroidal osteoma. To the best of our knowledge, this is the first report that $\mathrm{CNV}$ associated with choroidal osteoma may be implicated in subretinal pigmentation. We postulate that subretinal pigmentation around the $\mathrm{CNV}$ may be the result of phagocytized pigment by macrophages. Macrophages are innate immune cells that play a broad role in host defense and the maintenance of tissue homeostasis, and are especially common in trauma and inflammation. ${ }^{20}$ Furthermore, pathological tissues of choroidal osteoma 

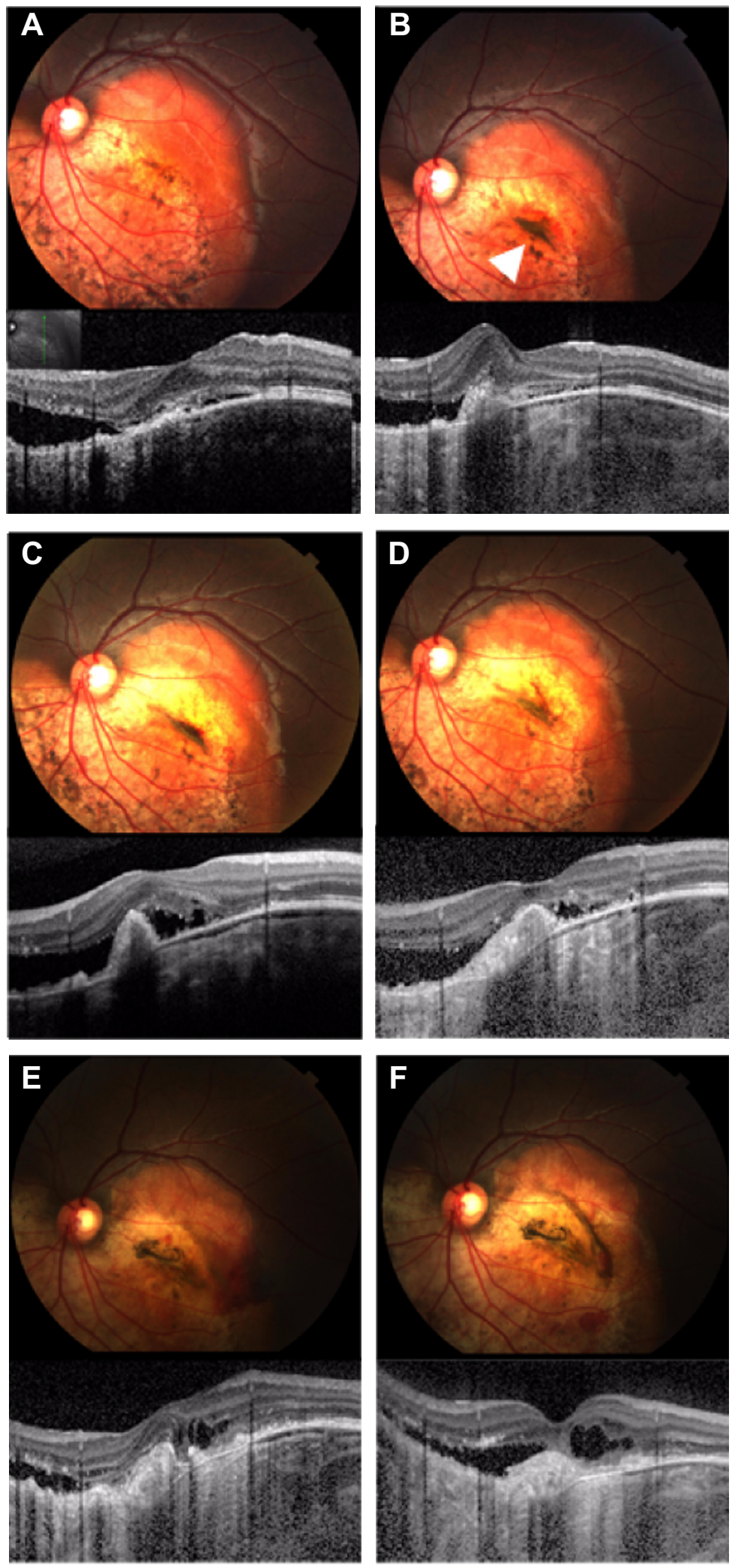

Figure 5 Photograph and spectral domain optical coherence tomography findings for case 3.

Notes: (A) First visit. Fundus photograph shows yellow-white and orange lesions of approximately four disk diameters in size. Insert shows fundus image for scan marking.

(B) One month after the first visit. Spectral domain optical coherence tomography shows choroidal neovascularization with subretinal fluid. Fundus photograph shows subretinal pigmentation (arrowhead) near the choroidal neovascularization. (C) Three months after the first visit. After the first intravitreal injection of bevacizumab, the subretinal fluid did not decrease. (D) Eight months after the first visit. Fundus photograph showing a pale subretinal pigmentation. (E) Twenty months after the first visit. Fundus photograph showing that the decalcified region and subretinal pigmentation were wider than observed at the first visit. (F) Twenty-five months after the first visit. The retinal pigment epithelium atrophy finally resulted in subretinal fluid and retinal edema. 
showed that macrophages exist in the retina overlying the tumor. ${ }^{21}$ Because a decalcified osteoma was associated with inflammation in the choroid and retina, it is possible that Müller and microglial cells of the retina secreted inflammatory cytokines such as interleukin (IL)-1, IL-6, IL-8, tumor necrosis factor- $\alpha$, and monocyte chemotactic protein-1.22,23 Macrophages induced by these inflammatory cytokines may migrate to the retina and phagocytize pigments derived from a destroyed RPE. ${ }^{24}$

The thickness of the choroidal osteoma was measured with ultrasonography and EDI-OCT. Some studies have shown a mean thickness of $1.2-1.4 \mathrm{~mm}$ and $921 \mu \mathrm{m}$ by ultrasonography and EDI-OCT, respectively., ${ }^{3,25}$ However, there has been no report of time-dependent tumor thickness changes. The present study showed that mean tumor thickness decreased from $709 \mu \mathrm{m}$ to $608 \mu \mathrm{m}$ at a mean of 41.0 months of follow-up. We previously reported that the calcified region of the choroidal osteoma became more contractive than was observed on the first visit, and the decalcified region was wider than was observed on the first visit. ${ }^{26}$ Progression of the decalcified tumor gave rise to contraction of the calcified region of the tumor. Therefore, decalcification of the tumor may decrease tumor thickness.

The limitations of our case series included relatively few patients and the use of a retrospective study because of the very rare type of tumor. Additionally, we lacked a definitive treatment protocol for every patient.

\section{Conclusion}

In conclusion, IVB for subfoveal CNV with a decalcified choroidal osteoma may have a limited role. Subretinal pigmentation with CNV as a result of a choroidal osteoma is an important marker. Hence, clinicians must note particularly the occurrence of secondary CNV when examining the appearance of subretinal pigmentation around the foveal area. In the future, larger studies could help elucidate the efficacy of antiVEGF drugs for CNV in cases of choroidal osteoma.

\section{Disclosure}

The authors report no conflicts of interest in this work. The authors alone are responsible for the content and writing of the paper and agree to allow Clinical Ophthalmology to review their data upon request.

\section{References}

1. Gass JD, Guerry RK, Jack RL, Harris G. Choroidal osteoma. Arch Ophthalmol. 1978;96:428-435.

2. Shields JA, Shields CL. Choroidal Osteoma. Intraocular Tumors: An Atlas and Textbook. 2nd ed. Philadelphia, PA: Lippincott Williams and Wilkins; 2008:264-271.
3. Shields CL, Sun H, Demiric H, Shilds JA. Factors predictive of tumor growth, tumor decalcification, choroidal neovascularization, and visual outcome in 74 eyes with choroidal osteoma. Arch Ophthalmol. 2005;123: $1658-1666$.

4. Foster BS, Fernandez-Suntay JP, Dryja TP, Jakobiec FA, D'Amico DJ. Surgical removal and histopathologic findings of a subfoveal neovascular membrane associated with choroidal osteoma. Arch Ophthalmol. 2003;121:273-276.

5. Shukla D, Tanawade G, Ramasamy K. Transpupillary thermotherapy for subfoveal choroidal neovascular membrane in choroidal osteoma. Eye. 2006;20:856-847.

6. Blaise P, Duchateau E, Comhaire Y, Rakic JM. Improvement of visual acuity after photodynamic therapy for choroidal neovascularization in choroidal osteoma. Acta Ophthalmol Scand. 2005;83:515-516.

7. Battaglia Parodi M, Da Pozzo S, Toto L, Saviano S, Ravalico G. Photodynamic therapy for choroidal neovascularization associated with choroidal osteoma. Retina. 2001;21:660-661.

8. Ahmadieh H, Vafi N. Dramatic response of choroidal neovascularization associated with choroidal osteoma to the intravitreal injection of bevacizumab (Avastin). Graefe's Arch Clin Exp Ophthalmol. 2007;245: 1731-1733.

9. Narayanan R, Shah VA. Intravitreal bevacizumab in the management of choroidal neovascular membrane secondary to choroidal osteoma. Eur J Ophthalmol. 2008;18:466-468.

10. Song MH, Roh YJ. Intravitreal ranibizumab in a patient with choroidal neovascularization secondary to choroidal osteoma. Eye. 2009; 23:1745-1746.

11. Song WK, Koh HJ, Kwon OW, Byeon SH, Lee SC. Intravitreal bevacizumab for choroidal neovascularization secondary to choroidal osteoma. Acta Ophthalmol. 2009;87:100-101.

12. Pandey N, Guruprasad A. Choroidal osteoma with choroidal neovascular membrane: successful treatment with intravitreal bevacizumab. Clin Ophthalmol. 2010;4:1081-1084.

13. Khan MA, DeCroos FC, Storey PP, Shields JA, Garg SJ, Shields CL. Outcomes of anti-vascular endothelial growth factor therapy in the management of choroidal neovascularization associated with choroidal osteoma. Retina. 2014;34:1750-1756.

14. Ruiz-Moreno JM, Arias L, Montero JA, Carneiro A, Silva R. Intravitreal anti-VEGF therapy for choroidal neovascularisation secondary to pathological myopia: 4-year outcome. Br J Ophthalmol. 2013;97: $1447-1450$.

15. Myung JS, Bhatnagar P, Spaide RF, et al. Long-term outcomes of intravitreal antivascular endothelial growth factor therapy for the management of choroidal neovascularization in pseudoxanthoma elasticum. Retina. 2010;30:748-755.

16. Zhang H, Liu ZL, Sun P, Gu F. Intravitreal bevacizumab for treatment of subfoveal idiopathic choroidal neovascularization: results of a 1-year prospective trial. Am J Ophthalmol. 2012;153:300-306.

17. Moisseiev E, Waisbourd M, Ben-Artsi E, et al. Pharmacokinetics of bevacizumab after topical and intravitreal administration in human eyes. Graefes Arch Clin Exp Ophthalmol. 2014;252:331-337.

18. Shima C, Sakaguchi H, Gomi F, et al. Complications in patients after intravitreal injection of bevacizumab. Acta Ophthalmol. 2008;86: 372-376.

19. Shields CL, Perez B, Materin MA, Mehta S, Shields JA. Optical coherence tomography of choroidal osteoma in 22 cases: evidence for photoreceptor atrophy over the decalcified portion of the tumor. Ophthalmology. 2007;114:53-58.

20. Gordon S, Martinez FO. Alternative activation of macrophages: mechanism and functions. Immunity. 2010;32:593-604.

21. Inomata H. Choroidal osseous choristoma. Rinsho Ganka. 1996;50: 16-17. Japanese.

22. Liu X, Ye F, Xiong H, et al. IL-1 $\beta$ Induces IL-6 production in retinal Müller cells predominantly through the activation of $\mathrm{P} 38 \mathrm{MAPK} / \mathrm{NF}-\mathrm{KB}$ signaling pathway. Exp Cell Res. Epub 2014 Sep 17.

23. Rao NA, Kimoto T, Zamir E, et al. Pathogenic role of retinal microglia in experimental uveoretinitis. Invest Ophthalmol Vis Sci. 2003;44:22-31. 
24. Luo C, Zhao J, Madden A, Chen M, Xu H. Complement expression in retinal pigment epithelial cells is modulated by activated macrophages. Exp Eye Res. 2013;112:93-101.

25. Freton A, Finger PT. Spectral domain-optical coherence tomography analysis of choroidal osteoma. Br J Ophthalmol. 2012;96:224-228
26. Yoshikawa T, Takahashi K. Decalcified choroidal osteoma found in the retina. Clin Ophthalmol. 2012;6:1823-1825.

\section{Publish your work in this journal}

Clinical Ophthalmology is an international, peer-reviewed journal covering all subspecialties within ophthalmology. Key topics include: Optometry; Visual science; Pharmacology and drug therapy in eye diseases; Basic Sciences; Primary and Secondary eye care; Patien Safety and Quality of Care Improvements. This journal is indexed on Submit your manuscript here: http://www.dovepress.com/clinical-ophthalmology-journal

\section{Dovepress}

PubMed Central and CAS, and is the official journal of The Society of Clinical Ophthalmology (SCO). The manuscript management system is completely online and includes a very quick and fair peer-review system, which is all easy to use. Visit http://www.dovepress.com/ testimonials.php to read real quotes from published authors. 